\title{
Poor Proficiency in English - A Blackman's Limiting Factor in Medical Education
}

"If a process is affected by more than one factor then its rate will be determined by the Factor which is nearest to its minimum value"

Blackman (1905)

The people of the third world Countries are clamouring for attention to the decline in the quality of the doctors being produced: One reason of this decline may be due to the burgeoning of large number of Government and Private Medical Colleges on populist demand, making quality control difficult.

But many Medical educationists feel the lack of proficiency in the English language among Medical Students and even Teachers could be an important cause of decline of Medical Education in non- English speaking Countries. It may be noted that medium of teaching and examination in such Countries is English. Invariably the Medical books are in English. Hence it becomes imperative for even a non-native speaker of English to gain a good or a reasonable proficiency in English, besides, learning his mother tongue and the National language (a real onerous task). Seemingly, the Medical Students taught and trained in a good English medium school do well than the Students who had no such opportunity. Such Students have motivation and perseverance but no comprehension of the Subject is possible due to the deficiency in English ( $A$ real Blackman's Limiting Factor).

It would be desirable for the 10+2 Syllabi makers to make the Syllabi of English more Language Centric than Literature Centric. This may not be construed as Sententious or a censorious comment.

Prof. S.M. Mishra MS (Surgery), MS (Ortho), FRCS Editor In Chief 